\title{
PEMBANGUNAN KIT VIDEO PEMBELAJARAN BAHASA MELAYU PENUTUR ASING BERTERASKAN BUDAYA
}

\author{
Developing Malay Language Learning Video Kit for Foreign Speakers based on Culture
}

\author{
Junaini Kasdan \\ junaini@ukm.edu.my \\ Yusmaniza Mohd Yusoff \\ yusmaniza.ukm@gmail.com \\ Nor Hashimah Jalaluddin \\ shima@ukm.edu.my \\ Hasnah Mohamad \\ hasnah_m@upm.edu.my
}

Universiti Kebangsaan Malaysia

\begin{abstract}
ABSTRAK
Kebanjiran tenaga kerja asing, seperti yang dilaporkan oleh Jabatan Imigresen Malaysia dan penetapan sasaran Kementerian Pendidikan Malaysia untuk menjadikan Malaysia sebagai hub pendidikan menjelang tahun 2020, merupakan peluang untuk mengembangkan bahasa Melayu kepada penutur asing. Namun, dalam keghairahan menyambut warga asing ini, perancangan dan tindakan yang tepat perlu diberikan perhatian. Mereka bukan sahaja perlu mempelajari bahasa Melayu, tetapi juga budaya Melayu yang pastinya berbeza dengan budaya kaum-kaum lain di Malaysia. Melalui kajian keperluan pelanggan yang dilakukan secara dalam talian, kajian ini mendapati bahawa lebih daripada $75.0 \%$ responden dari 17 buah negara memberikan maklum balas bahawa mereka tidak berminat untuk mempelajari bahasa Melayu, namun semua responden menyatakan ingin mempelajari budaya Melayu. Sejumlah 85.\% responden pula memberikan maklum balas bahawa mereka sukar untuk mendapatkan bahan pembelajaran dalam talian, khususnya dalam bentuk video yang boleh dirujuk. Susulan daripada itu, kajian ini bertujuan membangunkan kit video pengajaran dan pembelajaran bahasa Melayu untuk penutur asing dengan mengambil kira keperluan pengajaran bahasa dan budaya Melayu dalam satu pakej yang sama. Sebanyak 11 tema utama dipilih untuk membangunkan kit video ini dan telah diperkenalkan kepada pelajar asing yang mengikuti kursus bahasa Melayu di Institut Alam dan Tamadun Melayu, UKM dan di Foreign Language Centre, FCU Taiwan. Tahap awal kajian ini mendapati bahawa pelajar asing memberikan maklum balas yang positif terhadap kit video yang dibangunkan.
\end{abstract}

Kata kunci: Bahasa Melayu; penutur asing; kit video; budaya; pengajaran dan pembelajaran

\begin{abstract}
The flooding of foreign workforce as reported by the Malaysian Immigration Department and the aim of Ministry of Education Malaysia to make Malaysia an educational hub by the year 2020 are opportunities to spread and develop Malay language among foreign speakers. However, in the excitement of welcoming these foreign citizens, a plan towards Malay culture, especially for foreign speakers need to be given serious attention by all related parties. They do not only need to learn the Malay language, but they also need to learn the Malay culture, which obviously would be different compared to other cultures in Malaysia. Through an online customer needs survey, it was found that more than $75.0 \%$ of respondents from 17 countries were not interested in learning Malay language, however all respondents stated that they are interested in learning about the Malay culture. A total of $85.0 \%$ respondents stated that it was challenging to gain access to online learning materials, especially in the
\end{abstract}


form of videos. Due to the findings of the customer needs survey, this research intends to develop a Malay language teaching and learning video kit for foreign speakers, by considering the needs of teaching Malay language and culture in the same package. A total of 11 main themes were chosen in order to develop this video kit and it was introduced to the foreign students attending the Malay language course at The Institute of the Malay World and Civilization, UKM and Foreign Language Centre, FCU Taiwan. The initial stage of this research found that the foreign students responded positively to the video kit.

Keywords: Malay language; foreign speaker; video kit; culture; teaching and learning

\section{PENDAHULUAN}

Jabatan Imigresen Malaysia melaporkan bahawa terdapat sejumlah 2320034 orang pekerja yang memiliki permit dan 91670 orang pelajar asing di Malaysia pada tahun 2012 dan bilangan tersebut terus meningkat dari semasa ke semasa. Bahkan pada tahun 2017, Kementerian Sumber Manusia, Malaysia menganggarkan terdapat lebih daripada 6.7 juta pekerja asing berada di Malaysia (Jabatan Imigresen Malaysia 2017). Dalam keghairahan menjadikan Malaysia sebagai hub pendidikan pula, Malaysia mensasarkan sejumlah 200000 pelajar asing belajar di Malaysia menjelang 2020. Penetapan sasaran ini merupakan peluang untuk mengembangkan bahasa Melayu kepada penutur asing. Namun, dalam keghairahan menyambut tetamu asing ini, perancangan dan tindakan yang tepat perlu diberikan perhatian. Mereka bukan sahaja perlu mempelajari bahasa Melayu tetapi juga budaya Melayu yang pastinya berbeza dengan budaya kaum-kaum lain di Malaysia.

Kebudayaan atau budaya merupakan bentuk majmuk daripada kata 'budi-daya' yang bererti 'budi dan akal', yang berasal dari kata Sanskrit 'buddhayah' (Koentjaraningrat, 1987). Istilah budaya itu sendiri berasal dari perkataan Latin, cultura (colo) yang bermaksud 'to tend', 'to cultivate' and 'to till' (Tucker, 1931). Sutan Takdir Alisyahbana (1989) mentakrifkan budaya sebagai keseluruhan yang kompleks yang terjadi daripada unsur-unsur yang berbeza, seperti pengetahuan, kepercayaan, seni, undang-undang, moral, adat istiadat dan pertuturan yang diperoleh manusia sebagai anggota masyarakat. Takrifan yang hampir sama dikemukakan oleh Van Maanen dan Laurent (1993:278), "The way we give logic to the world begins at birth with the gestures, words, tone of voice, noises, colours, smells, and body contact we experience... Our culture is what is familiar, recognizable, habitual." Selanjutnya, F.X. Rahyono (2009) mentakrifkan budaya sebagai sesuatu yang dapat dilihat, dirasai, dialami, dihayati oleh indera manusia sama ada dalam bentuk tutur bicara atau tindakan. Hal ini berbeza dengan pengertian kebudayaan yang lebih menjurus kepada nilai-nilai, sistem atau akal fikiran yang terkandung dalam budaya.

Dalam konteks kajian ini, pengkaji mendefinisikan budaya sebagai sesuatu yang berkaitan dengan cara hidup, kepercayaan, lambang, nilai kemasyarakatan atau objek kebendaan yang diwarisi secara turun-temurun yang tergambar melalui bahasa dan tindakan. Justeru, mempelajari budaya perlu dilakukan melalui pembelajaran bahasa atau sebaliknya, pembelajaran bahasa perlu melalui budaya. Hal ini sesuai dengan pendapat Liddicoat, Papademetre, Scarino dan Kohler (2003) yang mengatakan bahawa bahasa tidak semata-mata struktural, sebaliknya bersifat komunikatif dan sosial. Hal yang sama pernah dinyatakan oleh Hardley (2001) bahawa aspek budaya dan pengajaran bahasa, terutamanya dalam pengajaran bahasa untuk penutur asing adalah saling berkaitan dan tidak boleh dilihat secara terpisah. Hubungan erat antara bahasa dengan budaya ini dinyatakan oleh Sapir (2000:396), bahasa ialah paduan bagi 'realiti (hakikat) sosial' dan panduan 'simbolik' kepada budaya. Hal ini demikian kerana bahasa digunakan oleh masyarakat dan mempunyai pengaruh dalam menentukan budaya. Bahasa sebagai perantara untuk menggambarkan budaya sesebuah masyarakat. Menurut Cho Minsung dan Puteri Roslina (2016), interaksi antara bahasa dengan budaya membawa kepada kelangsungan hidup bahasa telah menjadi alat yang penting dalam mengkaji dan memahami budaya sesuatu masyarakat.

Hakikatnya, masyarakat umum cenderung melihat budaya dan bahasa sebagai dua hal yang perlu dipelajari dan dihayati secara terpisah. Hal ini tergambar melalui kajian keperluan pelanggan yang penyelidik lakukan bagi mengenal pasti keperluan penutur asing terhadap bahasa Melayu. Kajian dilakukan secara dalam talian dan terbuka kepada penutur asing di mana-mana sahaja selama 30 hari. 
Seramai 50 responden dari 17 buah negara telah memberikan maklum balas terhadap soal selidik ini secara sukarela. Kajian ini mendapati bahawa kesemua responden mengetahui bahasa Melayu merupakan bahasa rasmi Malaysia, namun hanya $22.0 \%$ responden berminat untuk mempelajari bahasa Melayu. Menariknya, kesemua responden menyatakan mereka ingin mempelajari budaya Melayu. Perbezaan peratusan tersebut memberikan gambaran bahawa masyarakat melihat bahasa dan budaya perlu dipelajari secara berasingan. Selanjutnya, berkaitan dengan bahan pengajaran dan pembelajaran pula, sejumlah $85.0 \%$ responden memberikan maklum balas bahawa mereka sukar untuk mendapatkan bahan pembelajaran dalam talian, khususnya dalam bentuk video, seiring dengan kemajuan teknologi, yang boleh dirujuk tanpa mengira masa dan tempat.

\section{PENGKAJIAN PENGAJARAN BAHASA DAN BUDAYA UNTUK PENUTUR ASING}

Penelusuran terhadap kajian yang mengangkat permasalahan tentang pengajaran bahasa dan budaya untuk penutur asing, serta kajian yang berkaitan dengan bahan pengajaran bahasa Melayu untuk penutur asing menemukan beberapa kajian yang dapat dijadikan panduan dan sempadan dalam melaksanakan kajian ini. Pada umumnya, kajian terdahulu mencatatkan tentang kurangnya bahan pengajaran bahasa Melayu yang boleh dirujuk, sama ada oleh pengajar mahupun pelajar. Hasnah Mohamad and Junaini Kasdan (2012) misalnya, mencatatkan bahawa halangan utama pelajar dan tenaga pengajar bahasa Melayu di Korea Selatan ialah ketiadaan bahan rujukan, sama ada dalam bentuk cetakan konvensional mahupun dalam bentuk lainnya menyebabkan minat pelajar untuk belajar bahasa Melayu menurun. Dalam hal ini, strategi dan bahan pengajaran yang sesuai perlu dirancang dengan lebih baik. Hal ini sesuai dengan hasil kajian yang dilakukan oleh Nor Zuhidayah Muhd Zulkifli and Siti Saniah Abu Bakar (2016), iaitu strategi dan minat belajar mempunyai hubungan yang sangat signifikan.

Menyentuh tentang bahan pengajaran, pengkaji mendapati bahawa pengajaran tentang bahasa dan budaya cenderung berkisar tentang keperluan terhadap penggabungjalinan kedua-dua elemen berkenaan ketika proses pengajaran dan pembelajaran dilaksanakan tetapi tidak diturunkan dalam bentuk bahan ajar yang mudah dicapai. Begitu juga sebaliknya, bahan pengajaran dalam bentuk video khususnya juga telah banyak dihasilkan dan boleh dicapai secara dalam talian tetapi tidak dilakukan secara terancang sehingga mengabaikan unsur budaya. Walau bagaimanapun, kajian-kajian tersebut turut diberikan perhatian untuk dijadikan panduan dan sempadan dalam melaksanakan kajian alternatif ini.

Mardian Shah Omar, Azman Rahmat dan Yusfarina Mohd Yussof (2017) pula berusaha melihat keupayaan pendekatan interaktif budaya dalam membantu pengajaran bahasa Melayu untuk penutur asing bagi meningkatkan kebolehan berbahasa, sekaligus memahami tentang dunia Melayu itu sendiri. Melalui kajian ini, pengkaji menggunakan kerangka teori yang diketengahkan oleh B. F. Skinner, yang menghubungkaitkan pengajaran dengan aspek rangsangan dan maklum balas. Dalam hal ini, pengkaji mengaplikasikan beberapa aspek budaya dalam berbahasa, seperti sapaan, penggunaan kata nama (pakaian, makanan, permainan dan sebagainya), penggunaan kata adjektif dan kata kerja. Pengkaji mendapati bahawa pendekatan pengajaran bahasa Melayu kepada penutur asing yang berasaskan interaktif budaya ini sesuai diaplikasikan untuk pelajar yang tetap dan bilangannya sedikit.

Selanjutnya, kajian tentang pertalian antara pengajaran bahasa untuk penutur asing dengan budaya juga turut dilakukan oleh Imam Suyitno (2015). Pengkaji menekankan bahawa tenaga pengajar bahasa Indonesia untuk penutur asing (BIPA) perlu mempunyai pengetahuan yang baik tentang budaya Indonesia. Pemahaman budaya dapat membantu tenaga pengajar menentukan bahan, pendekatan serta kaedah pengajaran dan pembelajaran yang tepat. Dengan itu mutu hasil pembelajaran lebih efektif dan sesuai dengan tujuan pelajar dan tujuan pembelajaran. Pengkaji lain yang turut mengangkat permasalahan tentang pembelajaran budaya dalam bahasa ialah Arief Setyawan, Sarwiji Suwandi dan St. Y. Slamet (2017). Penubuhan Masyarakat Ekonomi ASEAN (MEA) dilihat sebagai peluang untuk mengembangkan bahasa Melayu/Indonesia dengan jalan memperkenalkan budaya Indonesia kepada masyarakat ASEAN. Namun, sama seperti kebanyakan kajian lain, kajian kedua-dua penyelidik ini hanya membicarakan tentang keperluan menggabungkan pengajaran budaya dan bahasa untuk penutur 
asing dalam satu pakej tersendiri. Kaedah pengajaran dan bahan pengajaran hanya disentuh secara sepintas sebagai garis panduan dan tiada penjelasan secara terperinci tentang aktiviti yang dijalankan.

Dalam konteks bahan pengajaran atau alat bantu mengajar pula, Imam Suyitno (2007) melalui kajiannya merumuskan bahawa pengajaran bahasa Indonesia untuk penutur asing perlu memenuhi keperluan pengguna, antaranya ialah sapaan, ungkapan mudah yang digunakan sehari-hari, ayat mudah, bilangan, imbuhan dan yang paling penting, pengajaran perlu dilakukan dalam bahasa Indonesia. Dari segi bahan mengajar pula, pengkaji antaranya mencatatkan bahawa bahan video ialah satu daripada bahan mengajar yang berkesan. Pada hemat penulis, kajian yang dilakukan oleh Imam Suyitno diberikan perhatian khusus oleh penyedia alat bantu mengajar.

Berdasarkan kajian-kajian lalu, dapat diambil kesimpulan bahawa pembelajaran bahasa sepatutnya seiring dengan pembelajaran budaya kerana pendekatan ini memudahkan penutur asing untuk merasai, mengalami dan menghayati bahasa yang dipelajari. Namun, penyediaan bahan mengajar juga perlu mengambil kira keperluan penutur asing, dari aspek jarak, masa, dan teknologi masa kini.

Selari dengan cadangan yang telah diusulkan oleh pengkaji terdahulu, kajian ini telah membangunkan kit video pengajaran bahasa Melayu untuk penutur asing (peringkat asas) yang boleh dirujuk oleh sesiapa sahaja atau untuk tujuan pembelajaran dalam talian. Kit video yang dibangunkan turut mengambil kira aspek bahasa dan budaya Malaysia, khususnya budaya Melayu. Sesuai dengan perkembangan teknologi pada masa kini, banyak video yang berkaitan dengan budaya Melayu dapat diperoleh melalui laman-laman sosial atau capaian Internet yang lain. Namun, berbeza dengan videovideo lain, kit video yang dibangunkan adalah lebih terancang dan disesuaikan dengan dapatan hasil kajian yang lalu.

Kajian adalah berdasarkan pendekatan kebudayaan, iaitu suatu kaedah melihat sesuatu menggunakan kebudayaan sebagai kacamatanya (Parsudi Suparlan, 2009). Menurutnya, kebudayaan sebagai pedoman kehidupan masyarakat, memungkinkan individu untuk saling berkomunikasi tanpa menimbulkan salah faham. Hal ini kerana melalui pemahaman kebudayaan sebagai acuan untuk bertindak, maka setiap penutur dapat menjangkakan yang diinginkan oleh lawan bicaranya, termasuk simbol-simbol atau bahasa tubuh yang digunakan. Dalam konteks individu, pengalaman budayanya adalah berbeza, bergantung kepada pengalaman yang diperoleh daripada lingkungannya.

\section{METODOLOGI KAJIAN}

Kajian ini berteraskan kajian kualitatif yang melibatkan kaedah pemerhatian dan pelibatan langsung penutur asing. Kajian kualitatif menggariskan beberapa proses untuk memastikan data yang diperoleh mempunyai keesahan dan kebolehpercayaan yang tinggi, namun tidak melalui prosedur statistik atau bentuk pengiraan lain (Strauss \& Corbin 1990). Dalam kajian ini, penulis membahagikan kajian kepada tiga tahap dengan menandai setiap tahap sebagai (i) pengenalpastian, (ii) pembinaan dan (iii) pengukuhan.

a) Tahap pengenalpastian

Pada tahap ini, maklum balas keperluan pengguna dilakukan dengan mengedarkan soal selidik yang dibangunkan khusus untuk kajian ini kepada penutur asing secara terbuka dalam laman web dan melalui e-mel individu yang dikenal pasti. Tujuannya adalah untuk memastikan keperluan penutur asing diambil kira dalam membangunkan kit video yang disarankan. Hasil dapatan kajian keperluan pengguna ini tidak akan dibincangkan dalam penulisan ini.

b) Tahap pembinaan

Pada tahap ini, kit video dibangunkan berdasarkan tema-tema perbualan harian masyarakat di Malaysia. Setiap video memaparkan situasi perbualan yang biasa berlaku dengan berlatarbelakangkan budaya tempatan untuk tempoh tiga minit. Sebelum kit video dibangunkan, skrip video perlu disediakan terlebih dahulu dan diujikan kesesuaiannya. Tujuannya adalah untuk menghindari perkataan yang terlalu susah dan sukar untuk difahami atau ayat yang terlalu panjang sehingga boleh mengelirukan pelajar. Pelakon yang dipilih pula terdiri daripada guru yang sememangnya sudah biasa dengan proses pengajaran dan pembelajaran, serta mempunyai 
kemahiran dalam seni lakonan. Selanjutnya, kit video yang telah dibangunkan perlu melalui proses penyemakan dan penyuntingan bagi mengelakkan sebarang kecacatan.

\section{c) Tahap pengukuhan}

Setelah kit video dibangunkan, kit tersebut diperkenalkan kepada pelajar melalui kelas pembelajaran bahasa Melayu peringkat asas, khususnya pelajar Kursus Intensif Keterampilan Bahasa Melayu (KIKBM) di Institut Alam dan Tamadun Melayu (ATMA) dan pelajar Malay Language di Foreign Language Centre, Feng Chia University, Taiwan. Semua maklum balas yang diterima dicatatkan untuk dianalisis dan penambahbaikan.

\section{DAPATAN KAJIAN}

Sesuai dengan namanya, 'kit video', maka kajian ini secara khusus bertujuan membangunkan video pendek untuk memberikan capaian yang lebih luas kepada penutur asing yang ingin mempelajari bahasa Melayu secara kendiri. Kit video dengan jenama 'Rakan Bahasa' ini boleh dicapai secara atas talian melalui laman web, http://www.ukm.my/kitbm/ms/ yang dibangunkan untuk tujuan pengembangan pengajaran dan pembelajaran bahasa Melayu untuk penutur asing. Gambar 1 merupakan paparan antara muka ciri khas kit video yang dibangunkan. Logo dan latar belakang disesuaikan dengan konsep pengenalan budaya tempatan dan telah mendapat perlindungan harta intelek (IP). Empat warna yang digunakan, merah, putih, biru dan kuning merupakan warna bendera Malaysia. Dua ikon lelaki dan perempuan, menggambarkan penutur jati bahasa Melayu dan sesuai dengan Perlembagaan Persekutuan bahawa Melayu hendaklah beragama Islam yang sentiasa ramah untuk menjadi rakan bahasa kepada penutur asing.

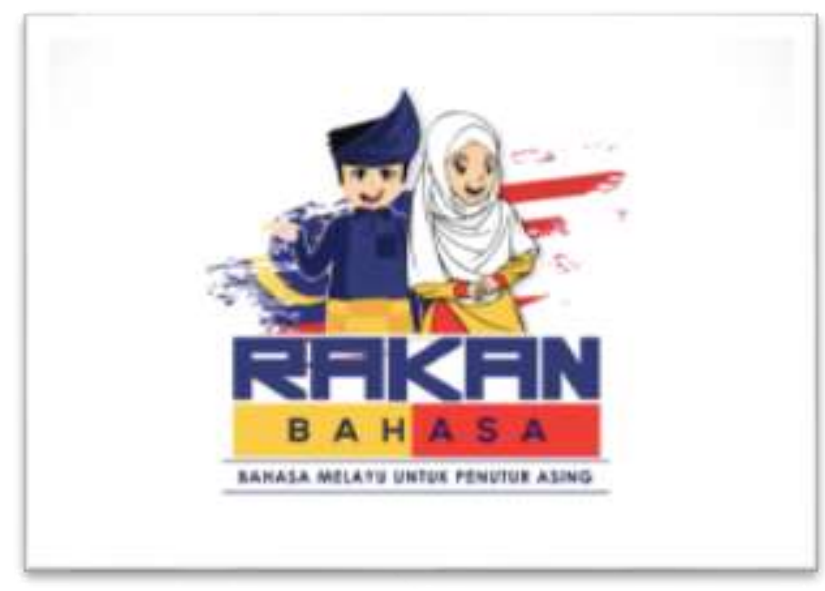

GAMBAR 1 Paparan muka kit video bahasa Melayu untuk penutur asing.

Sebanyak 25 kit video telah dibangunkan berdasarkan 11 tema awal yang dipilih iaitu sapaan; pengenalan tentang keluarga; urusan di kaunter; masa dan arah; nombor telefon; angka dan alamat rumah; alam sekitar dan cuaca; makanan; perayaan; pekerjaan; pengenalan tentang permainan rakyat/tradisional Melayu; dan cuti umum. Kit video yang dibangunkan dibahagikan kepada dua bahagian. Bahagian pertama memaparkan keseluruhan dialog dari tema yang dipilih. Tujuannya adalah untuk membiasakan pelajar mendengar dan melihat situasi sebenar yang berlaku dalam masyarakat. Sekiranya video digunakan dengan bantuan guru, maka guru boleh meminta pelajar mencatatkan perkataan-perkataan yang didengar dan dikenal pasti. Selanjutnya, pada bahagian kedua pula dipaparkan pengulangan keseluruhan perbualan. Setiap dialog diulang dan ditulis dalam bentuk bebola dialog agar dapat dibaca, ditiru dan difahami oleh pelajar, sekaligus memudahkan guru untuk memberikan penjelasan. Paparan perbualan adalah menggunakan bahasa baku. 


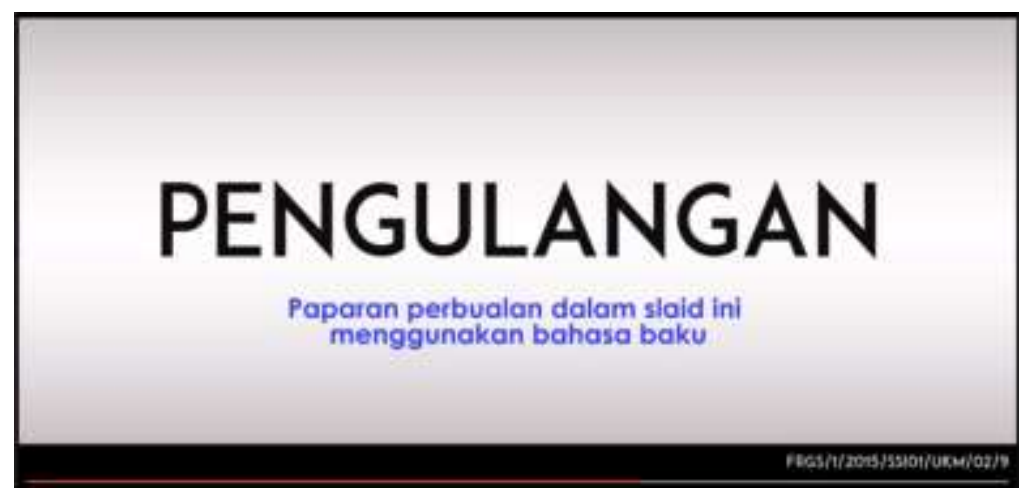

GAMBAR 2 Paparan muka bahagian pengulangan dalam kit video bahasa Melayu untuk penutur asing

Bagi tujuan penulisan ini, hanya pembangunan kit video bertemakan 'sapaan' dan 'perayaan' dibincangkan.

\section{i. Sapaan}

Sapaan merupakan kata-kata yang digunakan untuk menyapa seseorang atau panggilan yang terdiri daripada perkataan-perkataan yang digunakan untuk merujuk individu-individu tertentu berdasarkan atau dikaitkan dengan kedudukannya dalam masyarakat (Dewan Bahasa dan Pustaka, 1997). Perilaku seseorang ketika menyapa orang lain akan memberikan kesan pertama yang sangat mempengaruhi komunikasi dan interaksi selanjutnya. Sapaan yang sopan dan berbudi bahasa akan mewujudkan perbualan yang baik dan mewujudkan suasana yang lebih harmoni. Setiap bangsa ada cara menyapanya sendiri dan cara tersebut perlu dipelajari agar tidak berlaku salah faham. Dalam konteks penutur asing, Imam Suyitno (2007) menjelaskan bahawa pemilihan bahan pengajaran dan pembelajaran bahasa untuk penutur asing hendaklah disesuaikan dengan tahap kemampuan pelajar. Oleh itu, pada tahap asas, pelajar perlu diperkenalkan dengan kata sapaan terlebih dahulu, sesuai dengan budaya bahasa yang dipelajari.

Marlyna Maros and Mohd Baharim Mayidin (2011) berpendapat bahawa sapaan berbeza mengikut budaya dan masyarakatnya, apatah lagi dalam kalangan masyarakat Melayu yang mementingkan kesopanan, adat dan agama. Lakuan sapaan di Malaysia, terutama yang dilakukan oleh etnik Melayu, sangat bergantung pada faktor sosiopragmatik, seperti hubungan antara penutur, umur, jantina, status sosial, kuasa dan kedudukan (Amat Juhari, 1989). Oleh itu, muncullah sapaan seperti encik, tuan, puan, cik, pakcik, makcik, kakak, abang dan sebagainya. Bahkan terdapat juga kata sapaan gelaran akademik seperti Profesor, Doktor dan gelar kehormatan, seperti Tuanku, Tun, Tan Sri, Dato' Seri, atau Datuk yang apabila tidak digunakan pada tempatnya akan menyebabkan orang lain tersinggung. Sebagai contoh, pelancong Indonesia yang pertama kali datang ke Malaysia menyapa pegawai imigresen dengan panggilan 'makcik' dan 'pakcik' ketika melalui pemeriksaan keselamatan. Sapaan tersebut pasti terasa janggal, bahkan kurang sopan apabila dituturkan oleh orang yang lebih tua kepada orang yang lebih muda dan dalam situasi rasmi atau separa rasmi. Bagi mereka, hal ini bukan suatu yang aneh kerana mereka biasa mendengar sapaan tersebut digunakan dalam kalangan peniaga atau kawasan pelancongan di Indonesia yang biasa dikunjungi oleh pelancong Malaysia. Bagi sebahagian penutur asing yang lain pula, mereka cenderung menggunakan sapaan 'awak' atau 'kamu' untuk terjemahan you dan 'aku' untuk $I$ kepada sesiapa sahaja yang mereka temui, bahkan menggunakan nama panggilan seperti 'Tina', 'Mimi' atau 'Ros' walaupun untuk orang yang lebih tua atau orang yang dihormati. Hal ini biasa kerana bagi mereka sapaan itu biasa digunakan untuk menyebut diri seseorang tanpa mengira usia atau status. Tiada salahnya menggunakan kata sapaan tersebut tetapi harus kena pada tempatnya.

Oleh sebab kata sapaan dalam bahasa Melayu sangat penting, maka ungkapan ini perlu diajarkan kepada penutur asing pada peringkat awal pembelajaran. Orang Melayu mempunyai budaya sopan santun yang cukup tinggi, termasuk dalam hal memberikan sapaan kepada orang lain. Dalam 
membangunkan kit video pengajaran dan pembelajaran bahasa Melayu untuk penutur asing ini, kata sapaan diturunkan dalam tiga keadaan, iaitu (i) situasi dengan rakan sebaya, (ii) situasi dengan orang yang lebih tua, dan (iii) situasi rasmi.

Walaupun terlihat kecil, namun sering kali ada orang yang tersinggung kerana tidak disapa dengan betul. Orang yang menyapa pula akan sering dianggap sebagai tidak tahu adat atau kurang sopan. Misalnya, apabila orang Melayu menyapa orang Melayu yang lain atau dari kaum atau bangsa lain beragama Islam, aspek aurat berlainan jantina, hormat orang yang lebih tua dan berjabat tangan jika sama jantina diberikan perhatian yang khusus. Bagi penutur asing, mereka agak sukar untuk membezakan ucapan sapaan yang perlu digunakan. Hal seumpama inilah yang perlu dicontohkan dalam kit video yang dibangunkan. Contohnya, oleh sebab orang Melayu di Malaysia sinonim dengan agama Islam, maka sapaan akan dimulakan ucapan 'Assalamu'alaikum' yang membawa maksud 'selamat sejahtera ke atas kamu' akan diikuti dengan jawapan balas 'Waalaikumussalam' atau 'Waalaikum salam' yang bermaksud 'selamat sejahtera juga ke atas kamu'. Gambar 3 ialah contoh paparan sapaan untuk rakan sebaya, sesama penganut agama Islam dan jantina yang sama.

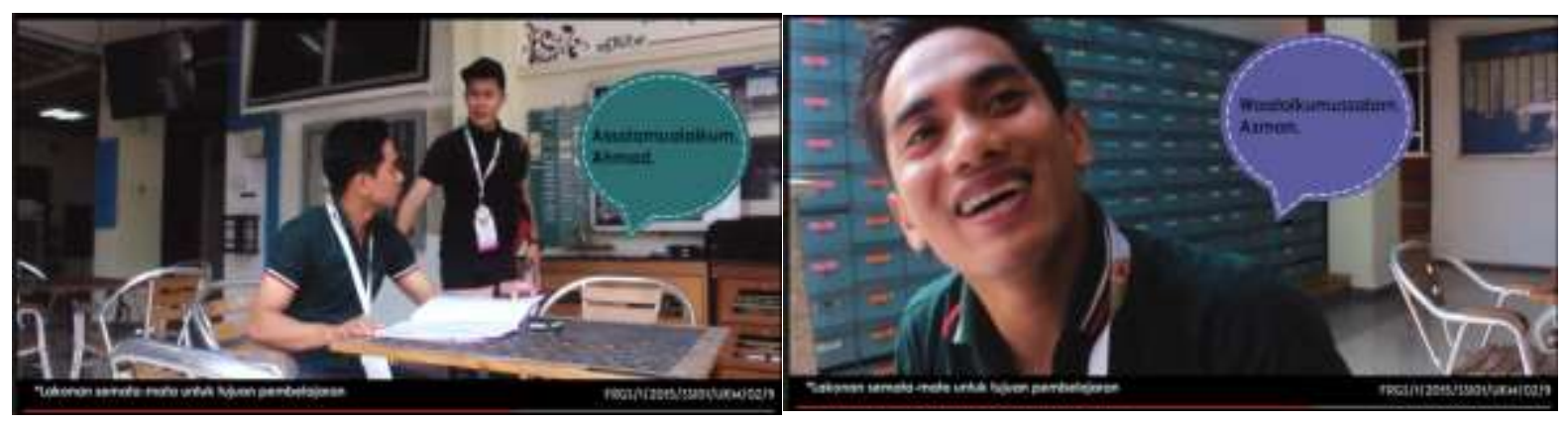

GAMBAR 3 Sapaan untuk penutur beragama Islam.

Ucapan salam daripada seorang bukan Islam kepada orang Islam atau sebaliknya bukanlah suatu kesalahan kerana tujuannya adalah untuk memberikan sapaan 'selamat' tetapi menggunakan bahasa yang berbeza, iaitu bahasa Arab. Namun, bagi kalangan orang Melayu sapaan tersebut bukan sekadar ucapan selamat, tetapi juga berkait dengan agama dan budaya. Sapaan ini apabila tidak sesuai dengan suasana dan tempat boleh mengundang pelbagai reaksi negatif. Oleh itu, bagi penutur asing, hal ini perlu dicontohkan supaya mereka dapat memahami, bukan sahaja bahasa Melayu tetapi juga budaya Melayu dan orang Melayu yang khususnya beragama Islam.

Selanjutnya, bagi memperlihatkan perbezaan sapaan antara kaum bukan Melayu atau yang bukan beragama Islam, bentuk sapaan yang berbeza pula dicontohkan. Lazimnya, apabila orang yang bukan beragama Islam berjumpa dengan rakan yang beragama Islam, ucapan sapaan yang digunakan ialah 'hai', diikuti dengan ucapan 'selamat pagi', 'selamat petang' dan sebagainya. Sapaan 'hai' digunakan kerana sifatnya yang universal, yang juga dituturkan oleh sesiapa sahaja. Ucapan selamat pula diucapkan mengikut kesesuaian waktu perbualan sedang berlangsung. Perlakuan sapaan ini turut dicontohkan dalam kit video yang dibangunkan (rujuk Gambar 4).

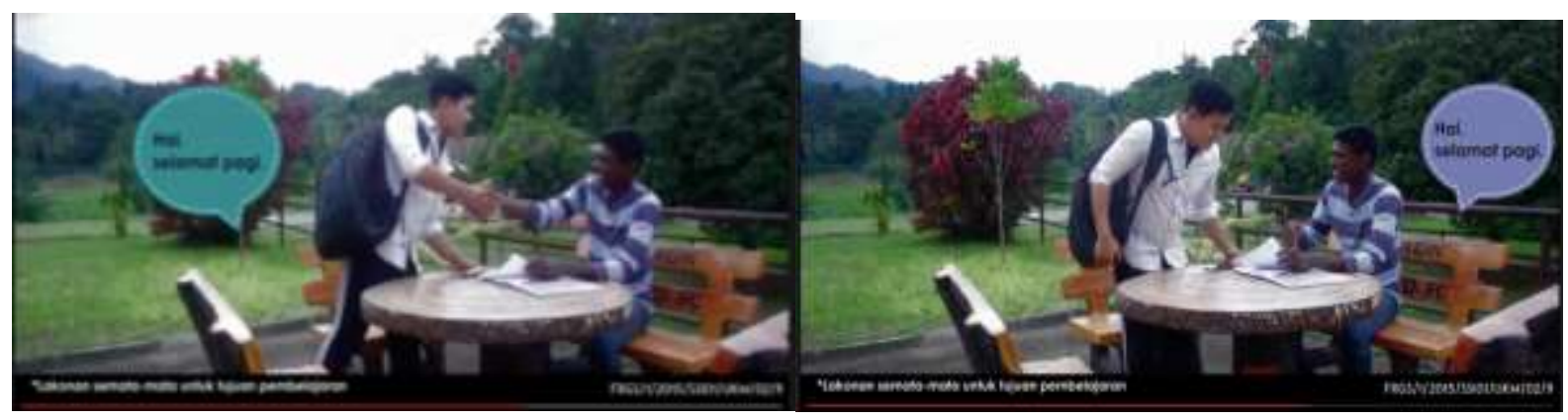

GAMBAR 4 Sapaan untuk penutur bukan beragama Islam. 
Melalui kit video ini juga dicontohkan ucapan sapaan untuk orang yang lebih tua, yang dikenali dan situasi yang tidak rasmi (lihat Gambar 5). Penggunaan kata 'abang' bagi merujuk kata ganti nama orang kedua yang usianya lebih tua sedikit daripada usia penutur. Kata 'abang' juga lazimnya diikuti dengan nama lawan bicara. Contohnya, 'abang Ayob'. Penggunaan panggilan 'abang' sahaja biasanya memberikan konotasi bahawa yang disapa merupakan keluarga terdekat kepada orang yang menyapa. Bahkan, sekiranya sapaan tersebut dituturkan oleh seorang perempuan, ungkapan tersebut akan menimbulkan pandangan kurang sopan. Oleh itu, dalam kit video ini dicontohkan penggunaan kata ganti nama 'abang' + nama lawan bicara.

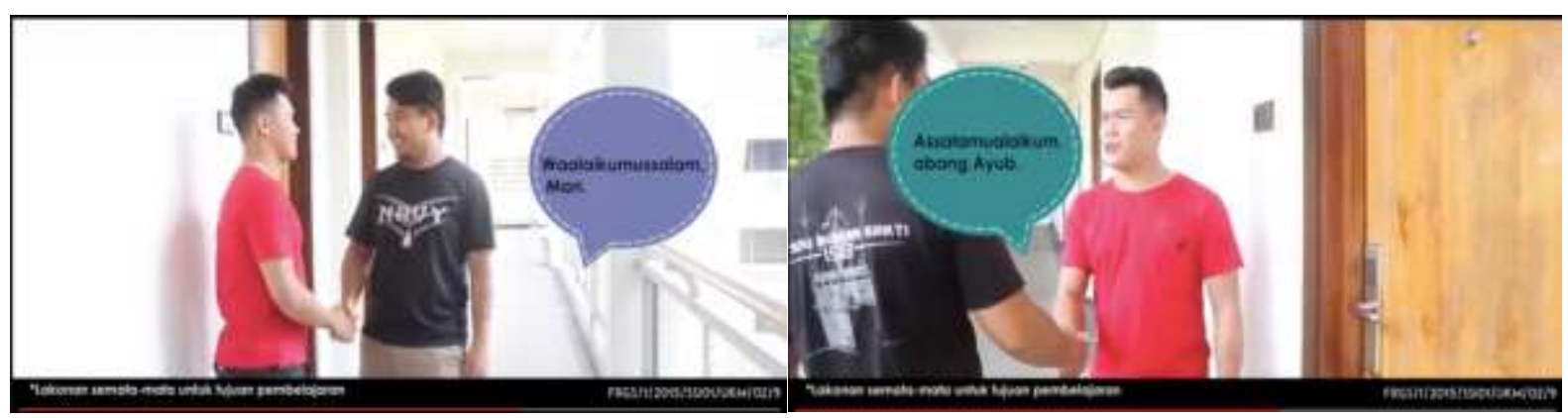

GAMBAR 5 Sapaan orang yang lebih tua.

Selain ucapan sapaan, melalui kit video ini juga dicontohkan kelaziman orang Melayu untuk berjabat tangan apabila bertemu, tanpa mengira agama. Hal ini bagi memberikan penjelasan bahawa dalam budaya Melayu, yang dipentingkan ialah keakraban dan keharmonian. Dengan berjabat tangan, seseorang akan berasa lebih dekat dan lebih selesa dan bersedia untuk meneruskan komunikasi selanjutnya. Dalam kit video ini juga dicontohkan tindakan yang lazim dilakukan oleh masyarakat Malaysia selepas berjabat tangan, iaitu meletakkan tangan di dada masing-masing (lihat Gambar 6). Perlakuan ini ialah simbol keakraban dan keikhlasan dalam persahabatan.

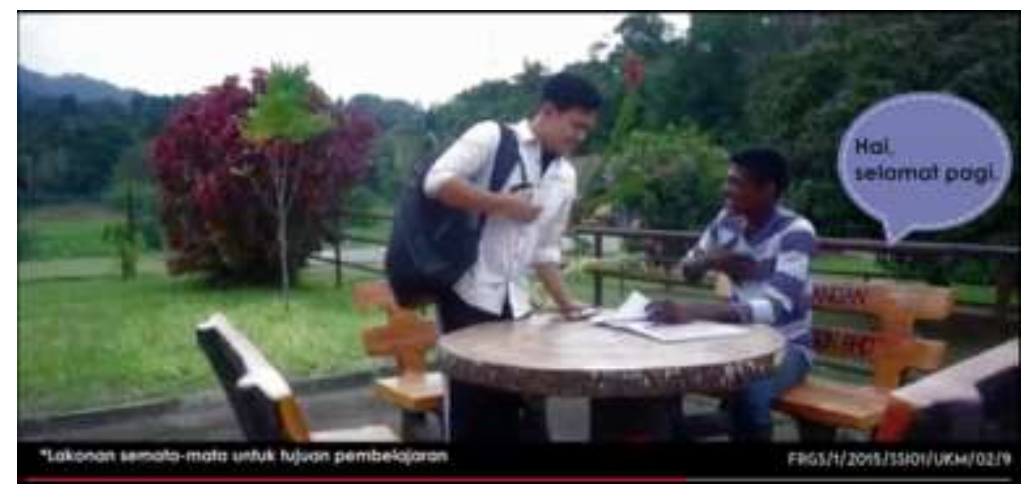

GAMBAR 6 Meletakkan tangan di dada selepas berjabat tangan.

Walau bagaimanapun, berjabat tangan tidak dicontohkan untuk penutur berlainan jantina kerana melanggar aturan budaya Melayu sebagai penganut agama Islam. Dalam konteks kit video sebagai bahan bantu dalam pengajaran dan pembelajaran bahasa Melayu untuk penutur asing ini, peranan guru masih diperlukan. Guru perlu menjelaskan dengan lebih lanjut, sama ada melalui kelas tatap muka atau kelas dalam talian.

\section{ii. Kata ganti nama}

Setelah dicontohkan dengan sapaan, pelajar juga diperkenalkan dengan kata ganti nama, sama ada dalam situasi rasmi atau tidak rasmi. Hal ini kerana budaya Melayu juga sangat mementingkan penggunaan kata ganti nama yang betul dalam perbualan. Kata ganti nama merujuk kepada kata yang 
digunakan untuk menggantikan kata nama, seperti 'saya', 'dia', 'awak', 'kamu' dan sebagainya. Menurut Amat Juhari (2001), penggunaan bahasa perlu disesuaikan dengan keadaan, suasana serta golongan dan peringkat yang berbeza. Nilai menghormati orang lain selalunya dikaitkan dengan penggunaan panggilan dan kata ganti nama. Kecenderungan masyarakat Melayu, khususnya dalam kalangan generasi muda pada hari ini adalah menggunakan kata ganti nama sendiri sebagai kata ganti nama diri pertama tanpa mengambil kira faktor sosial, seperti lawan bicara, situasi, waktu dan tempat. Misalnya, Ana, Shima, Lily, adik dan sebagainya yang turut digunakan secara meluas dalam urusan rasmi, misalnya di sekolah, kampus atau di pejabat. Penggunaan nama peribadi sebagai kata ganti nama bukan sahaja menyebabkan penutur asing keliru kerana kata ganti yang sedemikian tidak terdapat dalam bahasa dan budaya mereka, tetapi juga janggal pada pendengaran penutur Melayu sendiri. Penutur asing dari negara-negara barat pula sudah biasa dengan panggilan nama sebagai kata ganti diri kedua, walaupun mereka sedang berbicara dengan orang yang lebih tua atau yang lebih tinggi pangkat dan kedudukannya. Namun, hal ini berbeza dengan budaya Melayu yang penuh dengan adat dan sopan. Ada orang yang tersinggung hanya kerana tidak dipanggil dengan 'Datuk', 'Datin', 'Profesor' dan sebagainya.

Dalam hal ini, Amat Juhari (2001) membezakan kata ganti nama berdasarkan status sosial antara penutur dengan seseorang lawan bertutur. Biasanya, status sosial tersebut berkait dengan umur, pangkat dan keakraban. Semakin berusia, memiliki pangkat yang tinggi dan jauh keakraban perhubungan, maka penggunaan kata ganti nama seperti saya, awak, encik, tuan, puan hendaklah digunakan. Oleh sebab kata ganti nama ini penting, maka penggunaannya turut dicontohkan dalam kit video yang dibangunkan berdasarkan situasi yang berbeza. Sebagai contoh, penggunaan kata ganti nama diri kedua, 'encik' dan 'puan' ketika melakukan urusan rasmi (lihat Gambar 7).

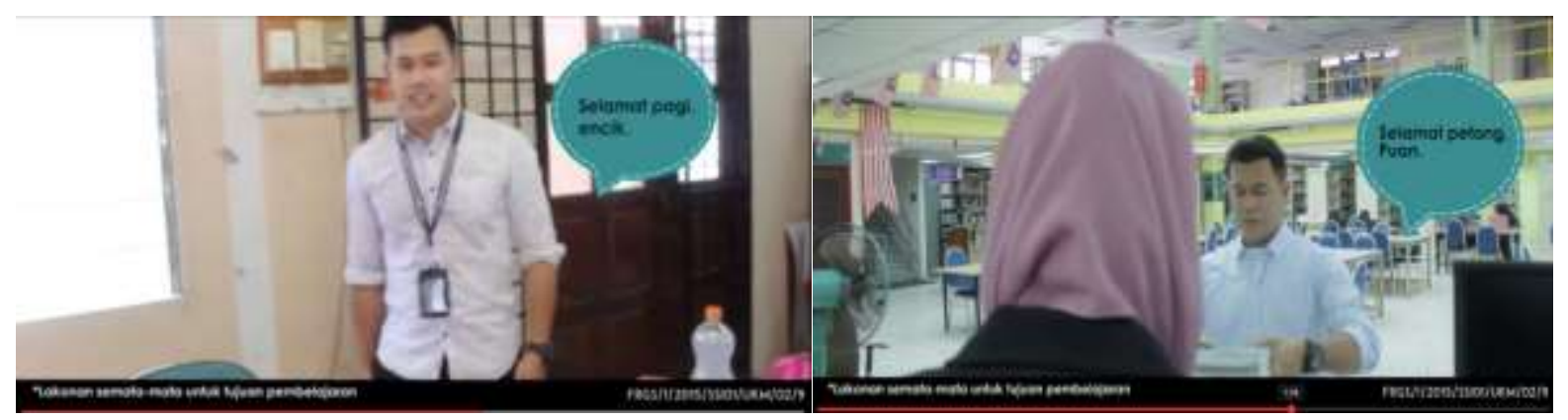

GAMBAR 7 Penggunaan kata ganti diri kedua 'encik' dan 'puan' untuk urusan rasmi

Walaupun dalam bahasa Inggeris juga terdapat kata panggilan sir dan madam, yang sesuai diterjemahkan dengan 'tuan' dan 'puan', namun sebahagian penutur asing lebih selesa menggunakan kata ganti nama you, yang dalam bahasa Melayu diterjemahkan sebagai 'awak' atau 'kamu'. Penggunaan kata ganti nama 'awak' dan 'kamu' termasuk kata ganti nama yang sopan apabila digunakan pada lawan bicara yang sesuai. Misalnya, rakan sebaya atau orang yang lebih muda. Namun, apabila digunakan untuk orang yang lebih dewasa yang lebih tinggi statusnya atau untuk urusan rasmi, panggilan tersebut dianggap kurang sopan atau tidak beradab.

Oleh sebab penutur asing sudah biasa dengan terjemahan 'aku' untuk $I$ dan 'kau' (engkau) untuk you, yang juga tidak salah digunakan dalam bahasa Melayu, maka kit video ini juga mencontohkan penggunaan tersebut tetapi dengan latar budaya yang berbeza. Kata ganti ini dituturkan untuk rakan sebaya yang sangat tidak sopan apabila digunakan kepada orang yang lebih tua atau tidak terlalu akrab (lihat Gambar 8). 


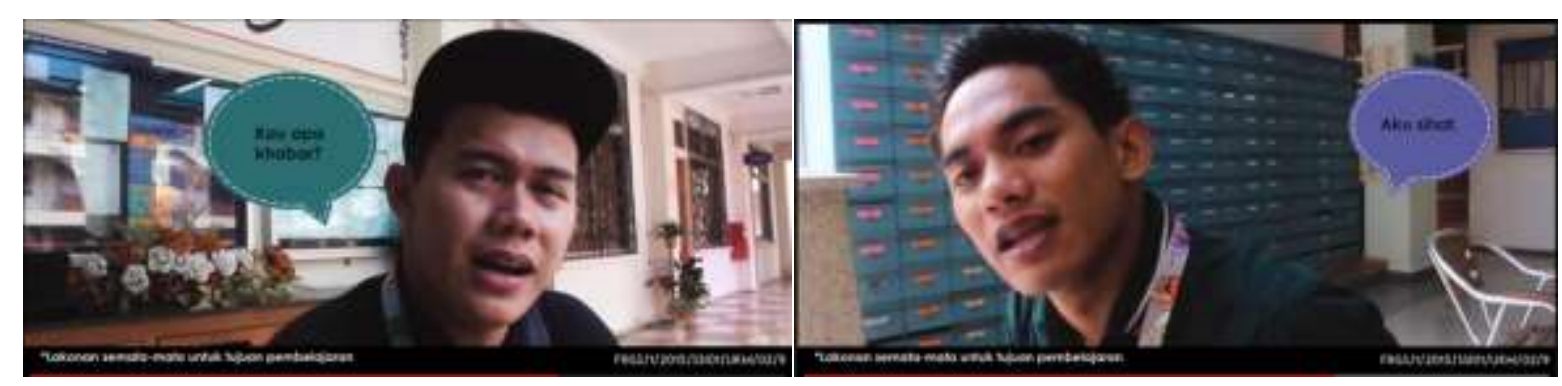

GAMBAR 8 Penggunaan kata ganti nama 'aku' dan 'kau'

Walaupun penggunaan kata ganti nama ini sering didengari, namun penggunaannya hendaklah secara berhati-hati. Golongan yang lebih muda dilarang menggunakan kata ganti nama 'aku' dan 'kau' terhadap orang yang lebih tua kerana dianggap kasar dan tidak bersantun. Selain itu, penggunaan 'aku' dan 'kau' perlu dielakkan dalam situasi rasmi kerana bertujuan menghormati majlis, hadirin, orang sekeliling, dan bagi memudahkan urusan.

Dalam situasi yang lebih rasmi, penutur asing juga dicontohkan dengan kata ganti diri pertama, 'saya' yang lebih bersifat umum dan sesuai digunakan dalam semua keadaan. Melalui kit video ini juga dicontohkan penggunaan kata ganti nama 'anda' (lihat Gambar 9) yang ada kalanya digunakan oleh orang yang lebih dewasa dan dalam urusan rasmi. Contohnya, guru di dalam kelas.

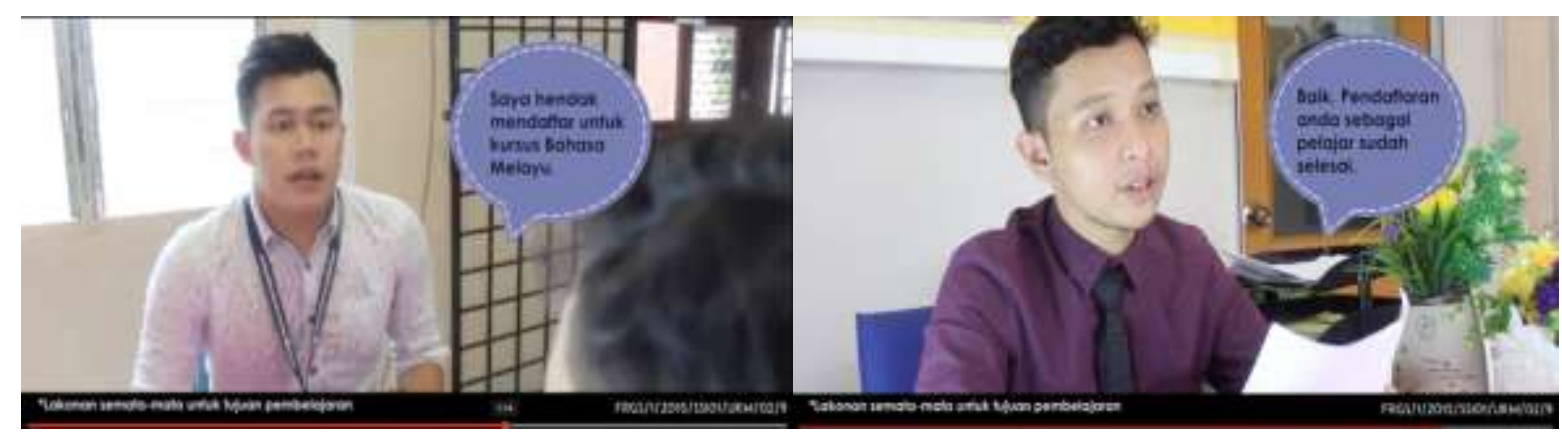

GAMBAR 9 Penggunaan kata ganti nama 'saya' dan 'anda'

\section{iii. Perayaan}

Malaysia terdiri daripada pelbagai kaum dan mempunyai keunikan budaya yang tersendiri. Setiap kaum mempunyai perayaannya sendiri termasuk kaum Melayu. Keunikan budaya yang sedemikianlah yang sangat diminati oleh penutur asing. Mereka selalu ingin tahu bagaimanakah perayaan ini disambut? Mengapakah perayaan ini disambut? dan sebagainya. Namun, mereka juga perlu tahu, apakah ucapan yang harus mereka tuturkan? Bagaimana ucapan itu dituturkan? Oleh itu, dalam kit video ini juga dicontohkan tentang perayaan di Malaysia, khususnya hari raya, yang diraikan oleh masyarakat Melayu. Melalui kit video ini penutur asing dicontohkan dengan ucapan yang lazim diucapkan ketika berkunjung ke rumah rakan atau jiran tetangga, iaitu 'selamat hari raya' (lihat Gambar 10). 


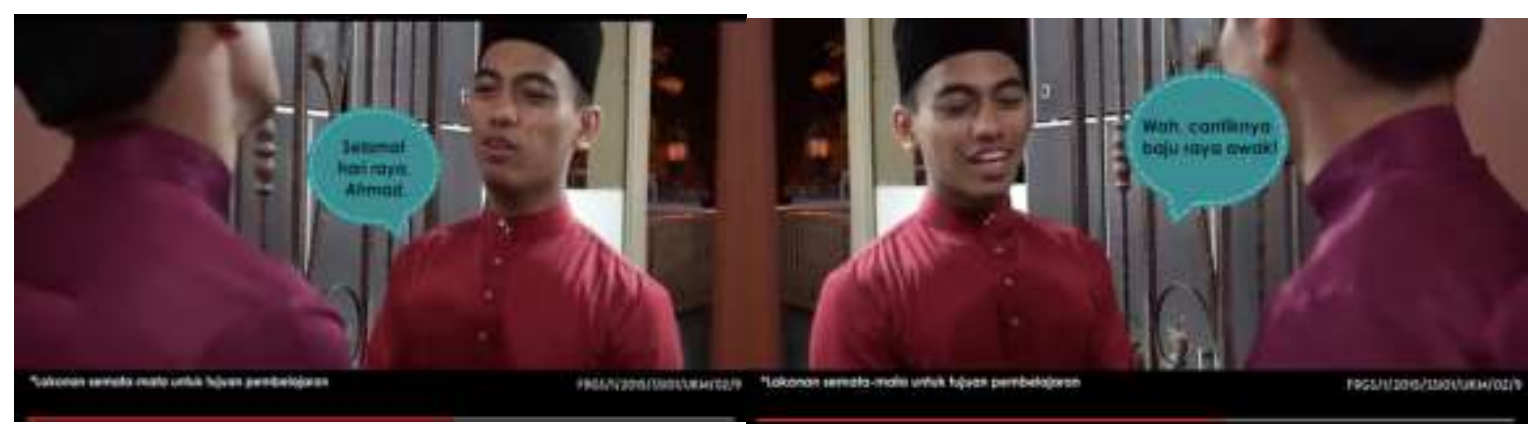

GAMBAR 10 Ucapan selamat dan pujian

Berpakaian cantik, khususnya pakaian tradisional Melayu, seperti Baju Melayu dan bersamping pada waktu hari raya juga dicontohkan dalam kit video ini. Dalam budaya lain, misalnya budaya penutur bahasa Inggeris, apabila melihat orang lain berpakaian cantik, mereka akan memuji dengan ungkapan 'nice cloth' dan sebagainya. Dalam budaya Melayu juga terdapat ungkapan memuji yang sedemikian. Oleh itu, melalui kit video ini turut dicontohkan ungkapan memuji yang lazim dituturkan, misalnya, 'Wah, cantiknya baju awak.' Daripada ungkapan ini, penutur asing boleh mengembangkan dengan ungkapan memuji yang lain, seperti 'Wah, banyaknya makanan.'; 'Wah, cantiknya rumah awak.' atau 'Wah, ramainya tetamu' dan sebagainya.

Selanjutnya, tuan rumah akan mempersilakan tetamu masuk ke rumah untuk berkenalan dengan keluarga atau untuk menjamu selera. Budaya ini juga tidak jauh berbeza dengan budaya penutur asing. Jika dalam bahasa Inggeris ada ungkapan 'please come in', maka dalam budaya Melayu dicontohkan dengan ungkapan 'jemputlah masuk', seperti dalam Gambar 11.

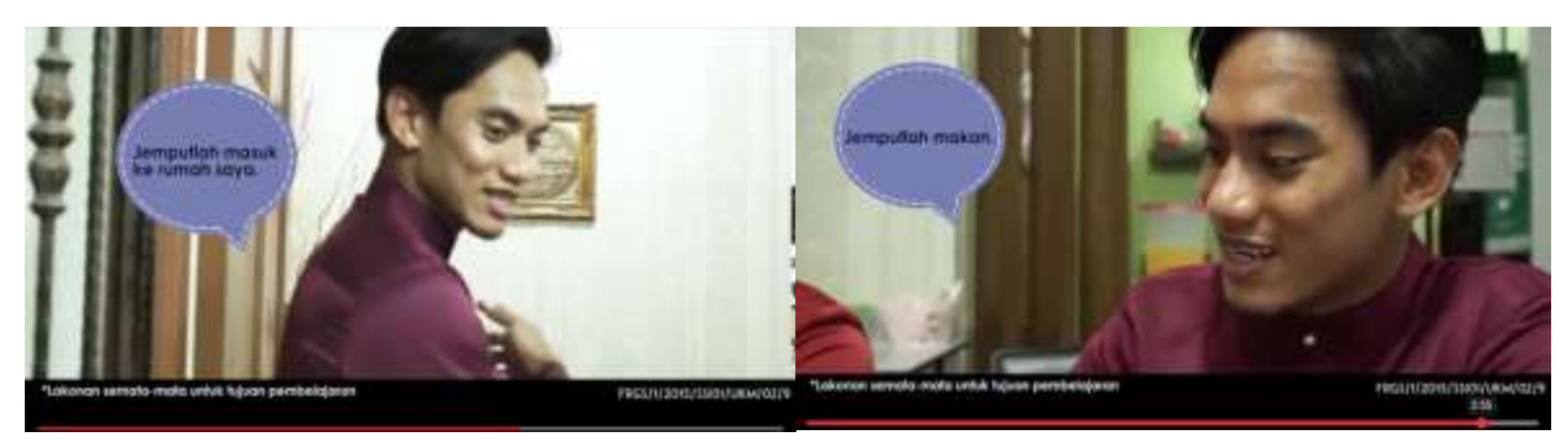

GAMBAR 11 Ucapan mempersilakan

Dalam beberapa aplikasi terjemahan, seperti google translate kata please diterjemahkan sebagai 'sila', sehingga ungkapan please come in diterjemahkan sebagai 'sila masuk.' Namun, dalam bahasa Melayu penggunaan 'jemputlah masuk' lebih menunjukkan sikap yang lebih akrab. Tetamu dijemput di hadapan pintu dan diiringi masuk ke rumah dengan penuh rasa hormat. Penggunaan kata 'jemput' juga dicontohkan ketika mempersilakan tetamu makan, misalnya 'jemputlah makan'. Ketika menuturkan ungkapan tersebut, tuan rumah berada bersama-sama tetamu untuk menemani tetamu makan sambil memperkenalkan makanan yang dihidangkan. Melalui kit video ini, tetamu diperkenalkan dengan makanan tradisional Melayu, seperti lemang, ketupat, sate, rendang dan sebagainya, seperti dalam Gambar 12. Dengan menonton kit video ini, diharapkan penutur asing yang baru ingin berjinak-jinak dengan bahasa Melayu dan berada di luar Malaysia akan dapat memahami bahasa dan budaya Melayu dengan lebih baik, sebelum mereka datang ke Malaysia. 


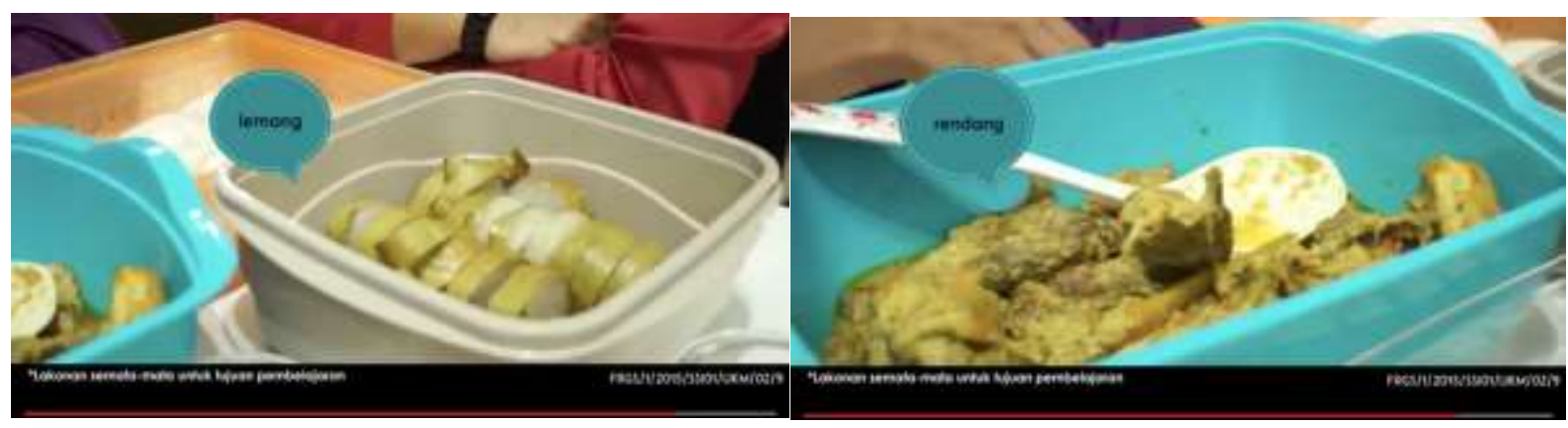

GAMBAR 12 Makanan tradisional

Bagi menarik minat penutur asing mempelajari bahasa Melayu juga, melalui kit video yang dibangunkan dipaparkan suasana kemeriahan perayaan tersebut disambut yang pastinya akan menggamit rasa ingin tahu penutur asing (lihat Gambar 12). Petikan lagu hari raya yang ceria turut menjadi muzik latar video, dan penutur asing dapat mengikutinya dengan mudah:

Selamat hari raya,

Aidil fitri mulia,

Ampun maaf dipinta,

Mencuci hening dosa,

Setahun menghilang,

Sekarang menjelang,

Selamat, selamat, selamat hari raya.

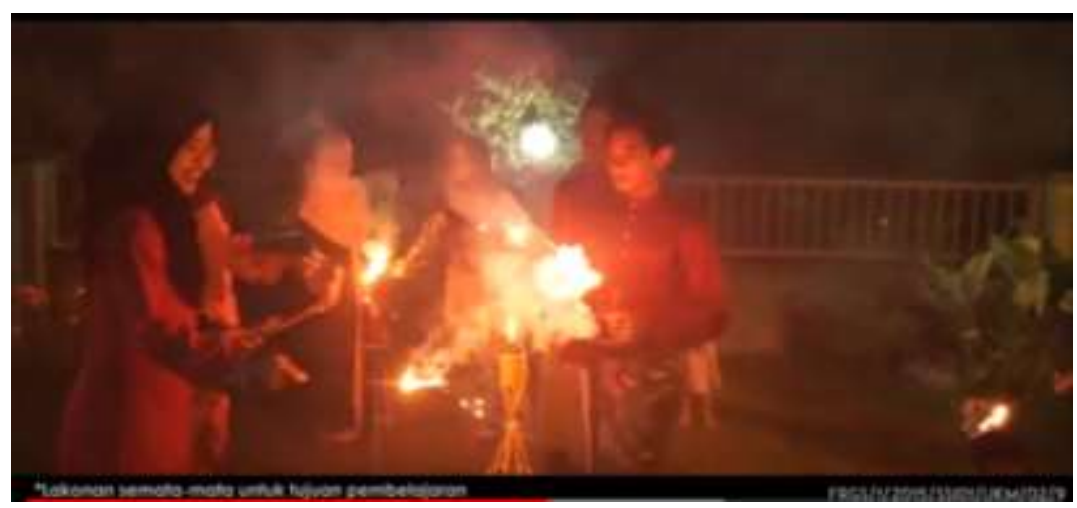

GAMBAR 13 Suasana malam hari raya

\section{iv Ucapan terima kasih}

Selanjutnya, setelah semua urusan atau kegiatan selesai, dalam budaya Melayu bahkan budaya-budaya lain juga semua orang akan merakamkan ucapan terima kasih sebagai tanda rasa dihormati, dihargai atau dipermudah dalam berurusan. Dalam bahasa Inggeris misalnya, orang sudah biasa dengan ucapan Thank you. Oleh itu, dalam kit video yang dibangunkan, penutur asing dicontohkan dengan budaya penggunaan ucapan 'terima kasih', yang mengandungi ungkapan rasa syukur atau rasa terhutang budi (Dewan Bahasa dan Pustaka, 2018) kerana telah dibantu atau telah dilayani dengan baik (lihat Gambar 13). Tidak memadai dengan ucapan, ungkapan tersebut harus disertai dengan wajah tersenyum sebagai tanda ikhlas. 


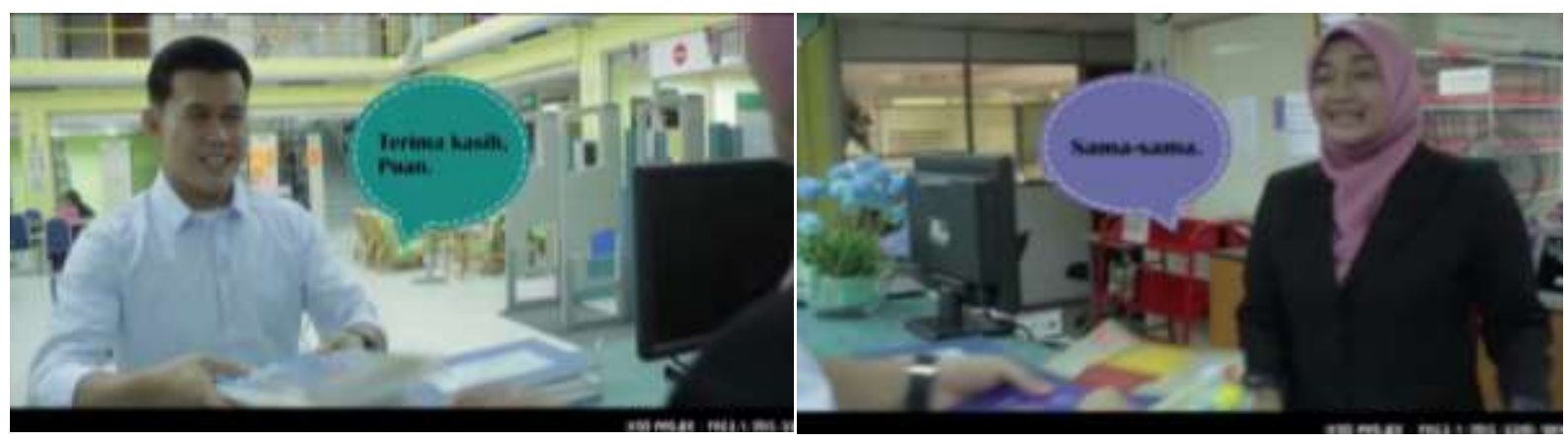

GAMBAR 14 Ucapan 'terima kasih' dan 'sama-sama'

Ucapan terima kasih dijawab dengan ungkapan 'sama-sama', yang bermaksud lawan bicara juga berterima kasih kerana telah berurusan dengan mereka atau telah menjayakan aktiviti bersama-sama mereka.

\section{KESIMPULAN}

Dalam mempelajari bahasa asing, Gumperz (1970) menjelaskan bahawa kajian tentang penggunaan bahasa perlu dilakukan dalam konteks sosial dan hubungannya dengan norma, nilai dan ciri-ciri budaya yang menguasai percakapan masyarakat tersebut. Mempelajari bahasa asing bukan sesuatu yang mudah. Maka dengan itu, pembelajaran bahasa asing seharusnya disertai dengan norma-norma yang berlaku dalam budaya masyarakat penutur bahasa tersebut. Penguasaan bahasa asing yang baik tidak hanya dilihat pada penguasaan linguistik tetapi juga turut dinilai berdasarkan penguasaan bahasa mengikut konteks, dan pemahaman budaya penutur natifnya. Bagi tujuan mengembangkan bahasa Melayu kepada penutur asing, baik di dalam mahupun luar negara, setiap lapisan anggota masyarakat perlu berusaha lebih keras untuk membantu merealisasikan matlamat mengantarabangsakan bahasa Melayu. Oleh itu, kajian seumpama ini dijalankan bagi meluaskan strategi pembelajaran bahasa kepada semua penutur asing tidak kira di mana-mana jua dalam bentuk pembelajaran atas talian yang merangkumi dua modul, iaitu bertulis dan multimedia. Pembelajaran berbantu guru pada masa kini dikatakan agak sukar kerana kekurangan masa dan motivasi kendiri oleh penutur asing. Maka, pemilihan pembelajaran secara kendiri berbantukan kit pembelajaran bahasa diharap dapat meningkatkan motivasi pengguna kerana sifatnya yang mudah dicapai di mana-mana sahaja. Pembelajaran melalui pemerhatian dan peniruan menggunakan kit video lebih mudah berbanding pembelajaran lainnya kerana boleh diulang-ulang dan bersifat semula jadi. Aspek bahasa, pemilihan grafik, teks, video dan animasi dan unsur-unsur budaya yang dipaparkan dapat memberikan perbezaan dan dapat membantu proses pembelajaran. Diharapkan kajian ini dapat menarik lebih banyak bahan pengajaran dan pembelajaran bahasa Melayu untuk penutur asing dalam pelbagai media yang lain, agar dapat dimanfaatkan oleh pelajar atau pengajar tanpa mengira masa dan tempat.

\section{RUJUKAN}

Amat Juhari Moain. (1989). Sistem panggilan dalam Bahasa Melayu: Suatu analisis sosiolinguistik. Kuala Lumpur: Dewan Bahasa dan Pustaka.

Amat Juhari Moain. (2001). Nilai rasa dalam Bahasa Melayu. Dlm. Yaacob Harun, Kosmologi Melayu. Kuala Lumpur: Akademi Pengajian Melayu.

Arief Setyawan, Sarwiji Suwandi, \& St. Y. Slamet. (2017). Pengenalan budaya lokal dalam pengajaran bahasa Indonesia bagi penutur asing (BIPA) di Indonesia melalui materi teks eksplanasi. The $1^{\text {st }}$ Education and Language International Conference Proceedings Center for International Language Development of 
Unissula. (http://www.jurnal.unissula.ac.id/index.php/ELIC/article/download/1218/927) [15 September 2018].

Cho Mingsun \& Puteri Roslina Abdul Wahid. (2016). Penterjemahan budaya bukan kebendaan dalam teks terjemahan bahasa Korea-bahasa Melayu. Jurnal Melayu. Bil 15(2): 160-175).

Dewan Bahasa dan Pustaka. (1997). Kamus linguistik. Kuala Lumpur: Dewan Bahasa dan Pustaka.

Dewan Bahasa dan Pustaka (2018). Maklumat kata. Diakses daripada http://www.prpm.dbp.gov.my

F. X. Rahyono. (2009). Kearifan budaya dalam kata (Edisi Revidi). Jakarta: Wedatama Widya Sastra.

Gumperz: J.J., (1970). Sociolinguistics and communication in small groups. Language behavior research laboratory. Berkeley: University of California.

Hardley A. O. (2001). Teaching Language in Context ( $3^{\text {rd }}$ ed.). University of Illinois: Heinle \& Heinle Thomson Learning.

Hasnah Mohamad \& Junaini Kasdan. (2012). Pengantarabangsaan bahasa Melayu: peluang dan hambatan, dalam Zaharani Ahmad, Chun Tai-Hyun \& Kim Jang-Gyem (peny.) Pengantarabangsaan bahasa Melayu di Korea: Isu, cabaran dan cadangan. Seoul: Hankuk University Foreign Studies Press.

Imam Suyitno. (2007). Pengembangan bahan ajar bahasa Indonesia untuk penutur asing (BIPA) berdasarkan hasil analisis kebutuhan belajar. Wacana. Vol.9 (1): 62-78.

Iman Suyitno. (2015). Pemahaman budaya dalam pembelajaran bahasa Indonesia bagi penutur asing (BIPA). Seminar Internasional menjadikan bahasa Indonesia sebagai bahasa Internasional. Malang, September 2015.(https://www.researchgate.net/ publication/315456935_Pemahaman_Budaya_dalam_Pembelajaran_Bahasa_Indonesia_Bagi_Penutur_Asin g_BIPA) [15 september 2018].

Khairi Abu Syairi. (2013). Pembelajaran bahasa dengan pendekatan budaya. Jurnal Dinamika Ilmu. Bil. 13, No.2Dis

Koentjaraningrat. (1987). Pengantar antropologi. Jakarta: Rineka Cipta.

Liddicoat, A.J, Papademetre, L, Scarino, L, \& Kohler, M. (2003). Report on intercutural language learning. Canberra: Australian Department of Education, Science and Training.

Mardian Shah Omar, Azman Rahmat, Yusfarina Mohd Yussof. (2017). Menyulam budaya dalam pengajaran bahasa Melayu penutur asing. Jurnal Linguistik Vol. 21(2) Disember: 81-92.

Marlyna Maros \& Mohd Baharim Mayidin. (2011). Jenis dan fungsi sapaan serta persepsi kesantunan dalam interaksi di kaunter pertanyaan. Jurnal Bahasa. 11(2), 219-226.

Nor Zuhidayah Muhd Zulkifli \& Siti Saniah Abu Bakar. (2016). Hubungan antara strategi pembelajaran bahasa Melayu dengan motivasi dalam kalangan pelajar di Jerman. Pendeta Journal of Malay Language Education and Literature. Jil. (7): 85-94.

Parsudi Suparlan. (2009). Pendekatan budaya terhadap agama. Daripada https://etnobudaya.net/2009/05/11/pendekatan-budaya-terhadap-agama/ [18 September 2018]

Sapir, E. (2000). The status of Linguistics as a science in Burke, Lucy (eds.) The Routledge Language and Cultural Theory Reader. London: Gordon Press.

Strauss, A., \& Corbin, J. M. (1990). Basics of qualitative research: Grounded theory procedures and techniques. Thousand Oaks, CA, US: Sage Publications, Inc.

Sutan Takdir Alisyahbana. (1989). The concept of culture and civilization: Problems of national identity and the emerging world in anthropology and sociology. Jakarta: Dian Rakyat.

Tucker, T. G. (1931). A concise etymological dictionary of Latin. Halle: Niemeyer.

Van Maanen \& Laurent. (1993). The flow of cultures in organization, theory, and the multinational corporation. New York: Ghoshal and Westney. 